\title{
PENGARUH EYE MOVEMENT DESENSITIZATION AND REPROCESSING (EMDR) DENGAN TEKNIK STABILISASI UNTUK MENURUNKAN POSTTRAUMATIC STRESS DISORDER (PTSD)
}

\section{THE EFFECT OF EYE MOVEMENT DESENSITIZATION AND REPROCESSING (EMDR) AND STABILIZATION TEHNIQUE TO REDUCE POSTTRAUMATIC STRESS DISORDER (PTSD)}

\author{
Ananda R. Rahmania \\ Moordiningsih \\ Fakultas Psikologi Universitas Muhammadiyah Surakarta \\ Email: tita.ananda@yahoo.co.id
}

\begin{abstract}
This study aims to empirically examine the therapeutic effect of differences in Eye Movement Desensitization and Reprocessing (EMDR) with Stabilization Technique in its application to persons with physically disabled in BBRSBD, Surakarta who suffered Post Traumatic Stress Disorder (PTSD). Participants of this study amounted to 9 people, men and women aged 17-33 years. Data collection tool used is the Impact Event Scale-Revised (IES-R). The method of data analysis used the analysis of variance (Anova). Based on the results of statistical tests, when the IES-R scale pre-test obtained value $F=0.153$, Sig $(p)=0.861, p>0.05$. Means no difference in levels of PTSD at the time of the pretest for EMDR, the technique of stabilization and control groups. While at post-test obtained value $F=7,168 ; \operatorname{Sig}(p)=0.026, p<0.05$. It shows a significant difference in levels of PTSD at post-test for the EMDR group, stabilization techniques and the control group and there is also a decrease rate of PTSD in the two groups were fed intervention.Based on this analysis, it can be concluded that the intervention of EMDR therapy group had a success rate in the reduction of PTSD better than the stabilization technique group and the control group and the group stabilization technique is not better than the EMDR but it's better than the control group.
\end{abstract}

Key word: EMDR, PTSD, IES-R, disabled, accident. 


\section{ABSTRAK}

Penelitian ini bertujuan untuk menguji secara empiris perbedaan pengaruh terapi Eye Movement Desensitization and Reprocessing (EMDR) dengan Teknik Stabilisasi dalam penerapannya terhadap penyandang tuna daksa di BBRSBD, Surakarta yang mengalami Post Traumatic Stress Disorder (PTSD). Partisipan penelitian ini berjumlah 9 orang, laki-laki dan perempuan berusia 17-33 tahun. Alat pengumpulan data yang digunakan adalah Impact Event Scale-Revised (IES-R). Metode analisis data yang digunakan adalah analisis varian (anava). Berdasarkan hasil uji statistik, pada saat prates skala IES-R diperoleh nilai $F=0,153$, Sig $(p)=0,861 ; p>0,05$. Berarti tidak ada perbedaan tingkat PTSD pada saat prates untuk kelompok EMDR, teknik stabilisasi dan kelompok kontrol. Sedangkan pada saat pascates diperoleh nilai $F=7,168$; $\operatorname{Sig}(p)=0,026 ; p<0,05$. Hal itu menunjukkan adanya perbedaan signifikan tingkatan PTSD pada saat pascates untuk kelompok EMDR, teknik stabilisasi dan kelompok kontrol dan juga ada penurunan tingkat PTSD pada ke dua kelompok yang diberi intervensi. Berdasarkan analisis tersebut, maka dapat disimpulkan bahwa intervensi terapi kelompok EMDR memiliki tingkat keberhasilan dalam penurunan tingkat PTSD lebih baik dibandingkan dengan kelompok teknik stabilisasi dan kelompok kontrol dan kelompok teknik stabilisasi tidak lebih baik dari kelompok EMDR namun lebih baik dari kelompok kontrol.

Kata kunci: EMDR, PTSD, IES-R, tuna daksa, kecelakaan.

Kecelakaan lalu lintas yang cukup parah bisa mengakibatkan cedera sementara ataupun menetap pada tubuhnya dan bisa juga mengalami kecacatan fisik berupa hilangnya sebagian anggota badan. Orang yang sebelumnya mampu beraktivitas dengan anggota badan yang lengkap dan hidup secara mandiri, setelah mengalami kecelakaan dan mengalami cacat fisik, hidup mereka menjadi berubah. Aktivitas sehari-hari menjadi terhambat, terbatas dan tidak jarang menjadi bergantung pada orang lain.

Menurut Biro Pusat Statistik (BPS), jumlah penyandang tuna daksa pada tahun 2006 tercatat berjumlah kurang lebih $10 \%$ dari jumlah penduduk Indonesia (250 juta jiwa). Sedangkan
Kementrian Kesehatan menyatakan 3,11 persen (6,7 juta jiwa) dari populasi penduduk Indonesia yang menyandang tuna daksa (harianjoglosemar.com). Menurut Direktur Keselamatan Transportasi Darat Ditjen Perhubungan Darat Kementrian Perhubunga, dari hasil analisis kecelakaan pada tahun 2010 sebanyak $67 \%$ dari korban kecelakaan berada pada usia produktif (22-50 tahun) (pikiran-rakyat.com).

Selain meninggalkan kecacatan fisik, kecelakaan lalu lintas juga bisa berakibat pada trauma psikologis. Menurut Diagnostic and Statistical Manual of Mental Disorder IV (Text Revision) atau DSM-IV-TR (2000), kecelakaan lalu lintas kemungkinan bisa menyebabkan trauma bagi korban yang terlibat, karena 
seseorang berhadapan secara langsung atau menyaksikan peristiwa yang mengakibatkan kematian, cedera serius, atau mengancam keutuhan fisik diri sendiri dan orang lain.

Orang-orang yang tidak bersalah dalam kecelakaan cenderung akan mengalami perasaan tidak berdaya. Pengemudi yang menyebabkan penumpang celaka (tanpa memerhatikan siapa yang salah) mungkin akan mengalami perasaan bersalah. Penelitian menunjukkan secara jelas bahwa individu yang mengalami luka serius dan menjalani perawatan di Rumah Sakit setelah mengalami kecelakaan kendaraan bermotor akan lebih menunjukkan reaksi stres. Penelitian lain menyatakan bahwa (1) orang-orang yang secara psikologis mengalami stres karena kecelakaan yang merasa ketakutan karena mungkin saja dirinya bisa meninggal akibat kecelakaan itu dan (2) orangorang yang menjalani proses peradilan sebagai akibat dari kecelakaan yang disebabkannya akan memiliki tingkatan trauma yang lebih tinggi (Galovski \& Veazey, 2001).

Para korban kecelakaan bisa jadi akan merasa ketakutan, mimpi buruk, dan bahkan halusinasi. NICE (National Institute for Clinical Excellence, 2005) menyebutkan bahwa, selain gejala-gejala psikis tersebut, gejala trauma dapat juga disertai gejala fisik seperti tubuh gemetar dan berkeringat yang semua gejala tersebut berlangsung selama minimal sebulan setelah kejadian kecelakaan lalu lintas. Trauma yang dialami tersebut akan mengganggu aktivitas sehari-hari terutama dalam hal produktvitas dan juga kebutuhan untuk bersosialisasi dengan orang lain akan terganggu. Belum lagi dengan kondisi fisik yang menjadi cacat maka mobilitas pun akan terhambat.

Setiap orang bisa memiliki reaksi yang berbeda terhadap peristiwa kecelakaan kendaraan bermotor. Ada yang merasa biasa saja dan terus menjalani kehidupannya dan ada pula yang memandangnya sebagai hal yang negatif dalam hidupnya dan menimbulkan reaksi stres serta beberapa dampak negatif lain dengan tingkatan yang berbeda-beda pada setiap orang. Reaksi stres yang disebabkan oleh kecelakaan kendaraan bermotor dapat terjadi pada berbagai macam cara dan pada tingkatan serta lama waktu yang berbeda-beda. Selain stres, juga dapat timbul adanya kecemasan atau panik saat harus kembali mengendarai atau menjadi penumpang kendaraan bermotor. Gejala yang timbul bisa berupa nafas yang pendek, jantung yang berdebar-debar, berkeringat, bergetar, kesulitan bernafas dan gangguan pandangan. Selama mengalami reaksi kecemasan, orang akan merasa kehilangan kendali dan ketakutan akan mengalami kecelakaan kendaraan bermotor lagi (Galovski \& Veazey, 2001).

Dampak dari stres tersebut dapat memengaruhi bagaimana kehidupan seseorang sehari-hari. Emosi positif 
dan negatif merupakan cermin dari pengalaman, peristiwa yang terjadi pada kehidupan seseorang yang memberi dampak pada dua hal tersebut. Studi mengenai stres dan kesejahteraan seseorang menunjukkan hasil yang berlawanan, antara peristiwa hidup yang membawa stres dengan kesejahteraan hidup seseorang. Studi juga menunjukkan bahwa emosi positif dan negatif membawa pengaruh pada performance saat kerja, kesehatan, hubungan personal, kreativitas dan pemecahan masalah (Perstling, 2012).

Sebagian dari penyandang tuna daksa setelah mengalami kecelakaan berfokus pada proses penyembuhan secara fisik dan kurang memerhatikan dampak psikologis berupa trauma. Padahal jika tidak kunjung ditangani keadaan akan menimbulkan stres berkepanjangan dan tanpa disadari dapat mengganggu proses dalam menjalani kehidupan pasca kecelakaan. Setelah pemulihan pun langsung berfokus pada bagaimana bertahan hidup dengan kondisi yang baru dan beradaptasi dengan situasi baru. Para korban kecelakaan cenderung mengabaikan apa yang dirasakan ataupun jika paham bahwa dirinya mengalami trauma, para korban tidak tahu harus berbuat bagaimana untuk keluar dari traumatiknya.

Sebagian dari penyadang tuna daksa yang bukan bawaan sejak lahir namun akibat dari kecelakaan berusaha memulai hidup baru setelah mengalami kejadian berat dalam hidupnya. Sebagian dari penyandang tuna daksa berusaha bangkit dengan mengandalkan bantuan orang sekitar dan keluarga. Sebagian yang lain memasuki suatu lembaga yang diperuntukkan bagi penyandang tuna daksa untuk membimbingnya agar mampu mandiri dengan kondisinya saat ini. Lembaga tersebut bisa berupa lembaga pemerintah maupun swasta.

Lembaga yang dikelola oleh pemerintah untuk membimbing penyandang tuna daksa bernaung pada Departemen Sosial. Lembaga tersebut adalah Balai Besar Rehabilitasi Sosial Bina Daksa (BBRSBD) "Prof. Dr. Soeharso" yang bertempat di Surakarta, Jawa Tengah. Balai Besar Rehabilitasi Sosial Bina Daksa (BBRSBD) Prof. Dr. Soeharso Surakarta adalah Unit Pelaksana Teknis di bidang Rehabilitasi Sosial Bina Daksa di lingkungan Depatemen Sosial Republik Indonesia yang berada di bawah tanggung jawab langsung kepada Direktur Jenderal Pelayanan dan Rehabilitasi Sosial, Resosialisasi Penyaluran dan Bimbingan Lanjut bagi penyandang tuna daksa agar mampu berperan dalam kehidupan bermasyarakat, Rujukan Nasional, Pengkajian dan Penyiapan Standar Pelayanan, pemberian informasi serta koordinasi dengan instansi terkait dengan peraturan perundang-undangan yang berlaku (Departemen Sosial RI Direktorat Jenderal Pelayanan dan Rehabilitasi Sosial Balai Besar Rehabilitasi Sosial Bina Daksa "Prof. DR. Soeharso", 2009). Dari hasil wawancara singkat dengan psikolog di 
BBRSBD, diperoleh informasi bahwa terdapat sejumlah siswa yang mengalami trauma akibat dari kecelakaan lalu lintas yang menyebabkannya menjadi cacat fisik. Hasil survei menunjukkan bahwa dari sekitar 250 siswa BBRSBD terdapat $34(13,6 \%)$ siswa laki-laki dan perempuan yang mengalami kecacatan diakibatkan oleh kecelakaan kendaraan bermotor dan $216(86,4 \%)$ siswa yang mengalami kecacatan sejak lahir. Dengan melakukan screening test melalui pemberian skala tes PTSD, yaitu Impact of Event Scale-Revised (IES-R) terhadap 34 siswa yang mengalami kecacatan diakibatkan oleh kecelakaan kendaraan bermotor, diperoleh bahwa $9(3,6 \%)$ di antaranya mengalami PTSD yang tinggi.

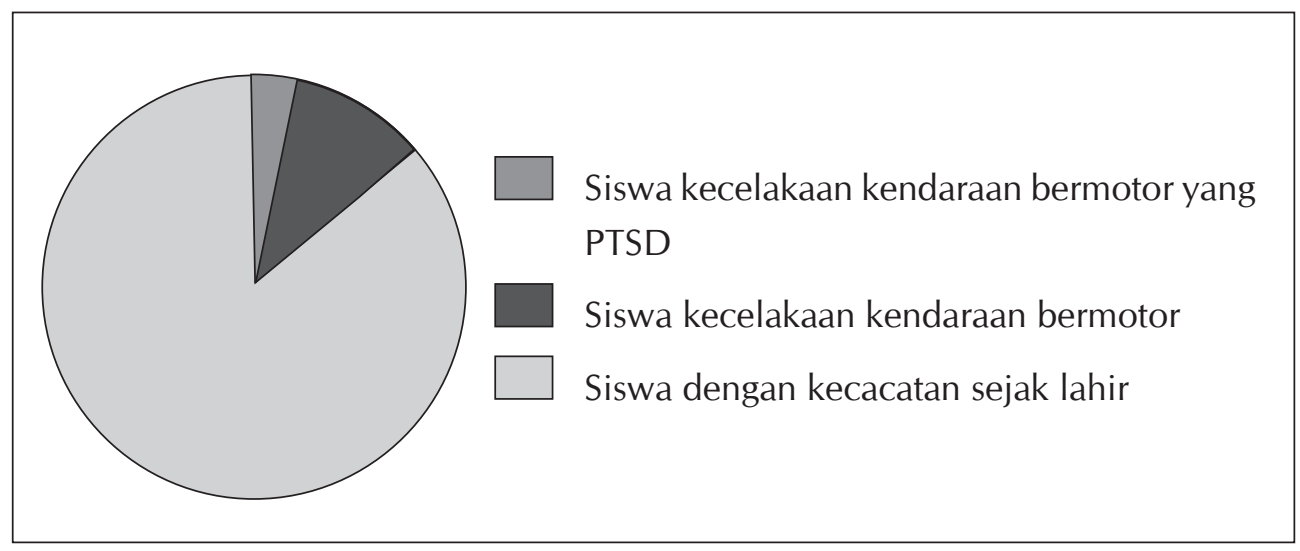

Gambar 1. Diagram Siswa Balai Besar Rehabilitasi Sosial Bina Daksa (BBRSBD)

Setelah mengalami kecelakaan berlalu lintas, terutama kecelakaan yang parah, seseorang bisa jadi mengalami trauma dan kemudian menjadi stres pascatrauma. Bila dibiarkan tidak teratasi, reaksi stres traumatis dapat menyebabkan efek berkepanjangan terhadap kesehatan mental (Bland dkk dalam Leitch, 2007).

Kessler (Leitch, 2007) menyatakan bahwa meskipun setelah beberapa tahun, simptom-simptom dari peristiwa traumatis akan tetap ada dan tidak berkurang secara spontan. Gangguan stres pasca trauma biasa disebut dengan PTSD atau
Post Traumatic Stress Disorder. PTSD merupakan gangguan yang terjadi ketika seseorang mengalami peristiwa traumatis yang bereaksi dengan ketakutan yang terus menerus, merasa tidak tertolong, dan horor, yang gejala-gejala tersebut berkembang selama minimal sebulan (American Psychiatric Association, dalam Taylor, 2003).

\section{Eye Movement Desensitization} and Reprocessing (EMDR) adalah metode bertahap yang secara keilmuan tervalidasi, pendekatan psikoterapi yang integratif berdasarkan teori mengenai 
psikopatologi yang disebabkan oleh pengalaman traumatis atau peristiwa yang mengganggu perjalanan hidup (EMDR International Association, 2009). Leitch (2007) menyatakan bahwa EMDR terbukti merupakan tritmen yang paling konsisten memberikan efek yang positif untuk mengatasi trauma. Sedangkan teknik stabilisasi merupakan bagian dari terapi EMDR namun lebih menekankan pada upaya menjaga dan mengembalikan fungsi dasar individu setelah terjadi gangguan.

Post Traumatic Stress Disorder (PTSD) merupakan sebuah gangguan kecemasan yang berasal dari peristiwa traumatis yang mencakup kematian atau yang mengancam jiwa, luka serius atau yang mengancam keutuhan fisik seseorang atau orang lain (Beck \& Coffey, 2005). Manual Diagnostik terbaru DSMIV-TR (APA, 2000) menjabarkan bahwa PTSD merupakan sebuah gangguan dengan beberapa kelompok gejala yang dapat berkembang mengikuti sebuah pengalaman traumatis yang ekstrim.

Topik ini menjadi penting untuk diteliti karena seseorang yang mengalami trauma akan merasa takut dan timbul kecemasan sewaktu-waktu. Hal tersebut akan berpengaruh dan mengganggu aktivitas sehari-hari seseorang yang mengalami trauma. Menurut peneliti sekaligus penemu terapi EMDR, Francine Saphiro, stimulasi bilateral dengan tepukan jari tangan dan gerakan jari dalam EMDR mampu untuk mengurangi rasa takut dan kecemasan serta mengubah kecemasan dan rasa takut menjadi proses belajar yang membuat seseorang yang mengalami trauma mampu untuk membentuk pertahanan diri dan mampu untuk bangkit dari traumanya (Shapiro, 2001). Dengan mengatasi atau menurunkan PTSD, diharapkan mampu untuk membantu mengurangi dampak trauma atau mengembalikan kondisi psikologis orang tersebut pada kondisi sebelum trauma supaya dapat melakukan kegiatan sehari-hari dengan lebih baik.

Tujuan dari penelitian ini adalah untuk mengetahui pengaruh intervensi EMDR dan teknik stabilisasi terhadap PTSD pada penyandang tuna daksa yang mengalami cacat karena kecelakaan lalu lintas. Adapun hipotesis pada penelitian ini adalah (1) ada perbedaan tingkatan stres pascatrauma antara sebelum dan sesudah intervensi EMDR dan teknik stabilisasi, (2) ada perbedaan tingkatan stres pascatrauma antara kelompok yang diberikan intervensi EMDR dan teknik stabilisasi dengan kelompok yang hanya diberi teknik stabilisasi saja dan dengan kelompok kontrol (tidak diberi terapi apapun).

\section{METODE PENELITIAN}

\section{Subjek Penelitian}

Subjek dalam penelitian ini berjumlah 9 orang, laki-laki dan perempuan dengan usia berkisar antara 17-33 tahun. Teknik pengambilan sampel 
menggunakan Quota Sampling, yaitu dengan cara mengambil 9 siswa binaan (6 siswa laki-laki dan 3 siswa perempuan) di BBRSBD dengan skor prates tertinggi, baik laki-laki maupun perempuan, dari 34 siswa (29 siswa laki-laki dan 5 siswa perempuan) yang mengalami kecacatan akibat kecelakaan kendaraan bermotor. 9 orang siswa tersebut dibagi 3 kelompok yaitu kelompok yang diberi intervensi terapi EMDR saja, teknik stabilisasi saja dan waiting list (control group) yang berjumlah masing-masing 3 orang per kelompok.

\section{Rancangan Penelitian}

Penelitian ini menggunakan kuasi eksperimen dengan Pre-test-Post-test Group Design. Desain ini membandingkan antara kelompok eksperimen yang hanya diberi terapi EMDR dengan kelompok yang hanya diberi teknik stabilisasi saja, sebelum dan sesudah diberikan tes (prates dan pascates) dan dengan kelompok waiting list yang hanya diberikan prates dan pascates tanpa diberi terapi apapun.

Kelompok eksperimen pertama, pada tahap awal diberi prates kemudian diberikan terapi EMDR dan dilanjutkan dengan pascates untuk dilihat perubahannya. Pada kelompok eksperimen kedua, dilakukan prates yang sama kemudian dilakukan terapi teknik stabilisasi dan dilanjutkan dengan pascates untuk diketahui perbedaannya. Pada kelompok ketiga, hanya diberikan pre dan pascates namun tidak diberi perlakuan terapi apapun untuk dibandingkan dengan kedua kelompok sebelumnya.

Tabel 1. Rancangan penelitian:

\begin{tabular}{cccc}
\hline $\mathrm{K} 1:$ & $\mathrm{Y} 1$ & $\mathrm{X} 1$ & $\mathrm{Y} 2$ \\
\hline $\mathrm{K} 2:$ & $\mathrm{Y} 1$ & $\mathrm{X} 2$ & $\mathrm{Y} 2$ \\
\hline $\mathrm{K} 3:$ & $\mathrm{Y} 1$ & $-\mathrm{X}$ & $\mathrm{Y} 2$ \\
\hline
\end{tabular}

\section{Keterangan :}

K1 : Kelompok Eksperimen dengan EMDR K2 : Kelompok Eksperimen dengan Stabilisasi

K3 : Kelompok Waiting List

Y1 : Prates

X1 : Perlakuan 1 (Terapi EMDR)

$-X$ : tanpa perlakuan

X2 : Perlakuan 2 (Teknik Stabilisasi)

Y2 : Pascates

\section{Metode Pengumpulan Data}

Untuk mengukur adanya PTSD dapat digunakan berbagai macam alat ukur PTSD yang sudah banyak berkembang saat ini. Salah satunya di pakai pada penelitian ini, yaitu IES-R atau Impact of Event Scale-Revised. Alat ini dibuat oleh Horowitz, Wilner, dan Alvarez pada tahun 1979 (IES) kemudian pada tahun 1997 direvisi menjadi IES-R oleh Weiss dan Marmar (Christianson, 2008). IES-R merupakan alat ukur dengan jenis self-report untuk mengetahui akibat dari suatu peristiwa yang terjadi pada diri seseorang. Skala ini terdiri dari 22 item berdasarkan tiga aspek dari PTSD, yaitu intrusion (ketergangguan), avoidance (penghindaran) and hyper arousal (kepekaan terhadap rangsang). 
Skala ini dapat digunakan untuk mengetahui tingkat stres dan PTSD seseorang setelah mengalami kejadian traumatis. Skala diberikan langsung kepada partisipan dan partisipan mengerjakan/ menjawab pertanyaan sendiri sesuai dengan keadaan partisipan dengan cara memilih salah satu dari pilihan jawaban yang tersedia. IES-R berisi pernyataan yang harus dipilih oleh partisipan berdasarkan tingkat frekuensinya. Pada penelitian ini IES-R juga digunakan untuk screening dan prates.

Berdasarkan Impact Event Scale (IES) reliabilitas pada alat tes ini memiliki koefisien alfa berkisar pada 0,89-0,94 dan konsistensi internal (Cronbach alpha) pada masing-masing subskala (intrusion $=0,87-0,94$, avoidance $=0,84-0,97$, hyperarousal $=0,79-0,91)$. Validitas pada alat tes ini yaitu IES merupakan alat tes yang sensitif dalam mengukur perubahan yang terjadi pada partisipan terutama yang berkaitan dengan simptom PTSD (Creamer dalam Australian Physiotherapy Association, 2010).

\section{Prosedur Intervensi}

Tahap pertama, persiapan intervensi dilakukan dengan pelaksanaan screening dan prates yang dilakukan pada tanggal 12 Mei 2012 di mushola asrama putra BBRSBD untuk siswa-siswa laki-laki dan di ruang makan asrama putri untuk siswa-siswa perempuan. Screening dan prates dilakukan pada pukul 10 pagi untuk siswa perempuan dan pukul 2 siang untuk siswa laki-laki. Jumlah siswa penyandang cacat akibat kecelakaan lalu lintas yang melakukan screening dan prates sebanyak 29 siswa laki-laki dan 5 siswa perempuan, total 34 siswa dari total keseluruhan siswa kurang lebih 250 siswa dengan berbagai sebab kecacatan. Kemudian diambil 9 siswa baik laki-laki maupun perempuan yang memiliki skor PTSD tertinggi untuk dijadikan subjek atau partisipan penelitian. Seluruh partisipan yang berjumlah 9 orang kemudian dibagi menjadi 3 kelompok masing-masing terdiri dari 3 orang, yaitu kelompok eksperimen EMDR dan Teknik Stabilisasi serta kelompok kontrol.

Selanjutnya pelaksanaan intervensi/ terapi EMDR untuk kelompok I dilakukan pada tanggal 4 Agustus 2012 di ruang konseling, BKPP, kampus Fakultas Psikologi UMS dan terapi Teknik Stabilisasi untuk kelompok II pada tanggal 7 Agustus 2012 di mushola asrama putra untuk siswa laki-laki dan ruang makan untuk siswa perempuan. Pemberian terapi masing-masing dilakukan dalam sehari. Untuk kelompok terapi EMDR masingmasing membutuhkan waktu 2 jam dan untuk teknik stabilisasi masing-masing partisipan membutuhkan waktu kurang lebih 30 menit.

\section{Teknik Analisis Data}

Analisis data menggunakan uji ANAVA dengan taraf signifikansi 5\% yang dilakukan sebelum dan sesudah 
perlakuan. Jika $\mathrm{p}$ sama atau kurang dari 0,01 berarti sangat signifikan, jika $p$ sama atau kurang dari 0,05 berarti signifikan, sedangkan jika $p$ lebih dari 0,05 berarti tidak signifikan (Hadi, 2004). Perhitungan selengkapnya akan menggunakan jasa komputer SPSS 17 Windows. Pembandingan hasil skor antara waktu pengukuran prates, pascates, dan tindak lanjut pada masing-masing kelompok dianalisis dengan ANAVA. Penulis memilih menggunakan ANAVA karena untuk membandingkan tiga kelompok penelitian tetap bisa dilakukan meskipun dengan subjek yang sedikit.

\section{HASIL PENELITIAN}

Berdasarkan penelitian yang dilakukan pada Sabtu, 4 Agustus 2012 pukul $11.00 \mathrm{~s} / \mathrm{d} 17.00$ WIB (masingmasing peserta $+/$ - 2 jam) dan Selasa, 7 Agustus 2012 pukul 13.00 s/d 14.30 WIB diperoleh hasil bahwa setelah pemberian intervensi terapi EMDR semua partisipan mengalami perubahan, yaitu menurunnya tingkat gejala PTSD. Berdasarkan hasil statistik uji ANAVA dapat dilihat pada saat prates diperoleh nilai $\mathrm{F}=0,153$, Sig $(p)=$ 0,$861 ; p>0,05$. Hal ini berarti tidak ada perbedaan tingkat PTSD pada saat prates untuk kelompok EMDR, teknik stabilisasi dan kelompok kontrol. Sedangkan pada saat pascates diperoleh nilai $F=7$, 168; Sig $(p)=0,026 ; p<0,05$. Hal ini menunjukkan nilai mean pada kelompok EMDR dan teknik stabilisasi mengalami penurunan dibanding dengan kelompok kontrol yang cenderung tetap. Itu berarti ada perbedaan signifikan tingkat PTSD pada saat pascates untuk kelompok EMDR, teknik stabilisasi dan kelompok kontrol dan juga ada penurunan tingkat PTSD pada kedua kelompok yang diberi intervensi.

Tabel 1. Deskripsi data Prates dan Pascates

\begin{tabular}{lccccccc}
\hline $\begin{array}{c}\text { Pre-test } \\
\text { IES R }\end{array}$ & N & Mean & $\begin{array}{c}\text { Std. } \\
\text { Deviation }\end{array}$ & $\begin{array}{c}\text { Post-test } \\
\text { IES R }\end{array}$ & N & Mean & $\begin{array}{c}\text { Std. } \\
\text { Deviation }\end{array}$ \\
\hline Kel EMDR\} $&{3} &{36.00} &{2.000} &{\text { Kel EMDR }} &{3} &{25.33} &{1.528} \\
{\text { Kel Stabilisasi }} &{3} &{36.67} &{3.055} &{\text { Kel Stabilisasi }} &{3} &{28.00} &{1.000} \\
{\text { Kel Kontrol }} &{3} &{35.00} &{5.292} &{\text { Kel Kontrol }} &{3} &{35.33} &{5.508} \\
{\text { Total }} &{\mathbf{9}} &{\mathbf{3 5 . 8 9}} &{\mathbf{3 . 2 9 6}} &{\text { Total }} &{\mathbf{9}} &{\mathbf{2 9 . 5 6}} &{\mathbf{5 . 3 4 1}} \\
{\hline}$
\end{tabular}




\section{PEMBAHASAN}

Hasil akhir yang diharapkan peneliti adalah mengetahui bahwa tingkat gejala PTSD penyandang tuna daksa yang diberikan terapi EMDR menurun. Penyandang tuna daksa yang diberikan intervensi terapi EMDR memiliki tingkat gejala PTSD yang lebih rendah dibandingkan dengan penyandang tuna daksa yang mendapat terapi teknik stabilisasi maupun yang tidak mendapat perlakukan apapun. Setelah dilakukan penelitian, diperolah hasil bahwa intervensi terapi EMDR lebih berpengaruh pada penyandang tuna daksa yang mengalami PTSD dibanding pemberian terapi teknik stabilisasi saja. Hal ini sesuai dengan pernyataan Leitch (2007) bahwa EMDR terbukti merupakan tritmen yang paling konsisten memberikan efek yang positif untuk mengatasi trauma. Pernyataan tersebut diperkuat oleh Rauch dan Cahill (2003) bahwa EMDR merupakan salah satu intervensi yang terbukti efektif dalam mengatasi trauma dengan mempelajari bahwa gerakan mata adalah hal unik yang memberikan keefektifan usaha untuk menyembuhkan suatu emosi yang kompleks akibat dari peristiwa traumatis atau peristiwa yang mengganggu perjalanan hidup.

Berdasarkan hasil analisis dan pembahasan, maka hipotesis yang penulis ajukan dapat teruji. Tingkat PTSD pada kelompok yang mendapat intervensi terapi EMDR lebih rendah daripada yang hanya mendapat intervensi terapi teknik stabilisasi dan juga daripada kelompok yang tidak mendapat perlakuan apapun.

Tidak bisa dipungkiri bahwa setiap penelitian pasti memiliki keterbatasan selama pelaksanaan penelitian tersebut, demikian juga halnya dengan penelitian ini. Penulis menyadari adanya kekurangan, kelemahan dan keterbatasan dalam pelaksanaan penelitian ini. Berikut beberapa di antaranya:

1. Keterbatasan jumlah partisipan penelitian yang sesuai dengan kriteria penelitian ini. Apabila partisipan lebih banyak, maka hasil penelitian bisa lebih akurat dan bervariasi.

2. Pelaksanaan terapi hanya sehari, padahal untuk hasil yang maksimal, terapi EMDR khususnya, memakan waktu yang cukup panjang dan memerlukan beberapa kali pertemuan, namun terapis yang berada jauh di Aceh, menyebabkan terbatasnya waktu pelaksanaan dan pemantauan.

3. Terbatasnya waktu partisipan karena mereka memiliki jadwal yang padat di BBRSBD dan memiliki jadwal untuk segera Praktek Kerja Lapangan dan kemudian lulus pulang ke kampung halaman masing-masing sehingga tidak bisa selalu memantau dan memberi tindak lanjut kepada mereka. 


\section{SIMPULAN DAN SARAN}

\section{Simpulan}

Berdasarkan hasil penelitian yang telah dijabarkan sebelumnya, dapat disimpulkan bahwa terapi EMDR memiliki pengaruh yang mampu menurunkan gejala PTSD. EMDR dapat menjadi alternatif terapi dalam mengatasi PTSD pada penyandang tuna daksa.

\section{Saran}

Berdasarkan dari hasil penelitian dan kesimpulan, maka beberapa saran yang perlu diberikan, antara lain:

1. Bagi peneliti selanjutnya, jika akan mengambil lokasi penelitian di BBRSBD, ada baiknya menggunakan subjek/partisipan dari siswa yang baru masuk/siswa baru karena siswa baru masih belum pernah diambil oleh peneliti lain sebagai bahan penelitian sehingga siswa masih belum jenuh, belum ada proses belajar dan mereka cenderung lebih mudah untuk menuruti instruksi yang ada.

2. Bagi partisipan, dengan adanya pelaksanaan terapi yang telah diadakan kemarin diharapkan para partisipan memperoleh manfaat dan dapat menerapkannya ke dalam kehidupan sehari-hari.

3. Bagi praktisi, intervensi EMDR dan teknik stabilisasi masih jarang diterapkan dan dikembangkan di Indonesia. Oleh karena itu perlu adanya penelitian sejenis terhadap konteks yang bervariasi dan populasi yang lebih luas.

\section{DAFTAR PUSTAKA}

American Psychiatric Association. (2000). Diagnostic and Statistical Manual of Mental Disorder IV (Text Revision).

Beck, J. G., Coffey, S. F. (2005). Group Cognitive Behavioral Treatment for PTSD: Treatment of Motor Vehicle Accident Survivors.

Cahill, S.P., Foa, E.B., Hembree, E.A., Marshall, R.D., Nacash, N. (2006). Dissemination of Exposure Therapy in the Treatment of Posttraumatic Stress Disorder. Journal of Traumatic Stress, 19. (5), 597-610.

Christianson, S. (2008). The Impact of Event Scale - Revised (IES-R). New York University of Nursing, issued number 19.

Depsos. (2009). Departemen Sosial RI Direktorat Jenderal Pelayanan dan Rehabilitasi Sosial Balai Besar Rehabilitasi Sosial Bina Daksa "Prof. DR. Soeharso". Surakarta: Depsos.

EMDR International Association. (2009). Definition of EMDR: Appendix $1 \mathrm{~A}$ (Executive Limitations of Appendix).

Galovski, T.E. \& Veazey, C. (2001). Surviving the Crash: Stress Teactions of Motor Vehicle Accident Victims. 
Hadi, S. (2004). Metodologi Research Jilid 3. Yogyakarta: Andi

Leitch, M.L. (2007). Somatic Experiencing Treatment with Tsunami Survivors in Thailand: Broadening the Scope of Early Intervention. Traumatology. 13:11. Sage Publications.

Perstling, M. (2012). Well-Being and Secondary Traumatic Stress of Social Workers in Namibia. Thesis: the University of Namibia.

Rauch, S.A.M. \& Cahill, S.P. (2003). Treatment and Prevention of Posttraumatic Stress Disorder. Cinical Focus Primary Psychiatry, 10(8), 60-65.
Shapiro, F. (2001). Eye Movement Desensitization and Reprocessing: Basic Principles, Protocols and Procedures (2nd ed.). New York: Guilford Press.

Taylor, S., Thordarson, D.S., Fedoroff, I.C., Maxfield, L., Lovell, K., \& Ogrodniczuk, J. (2003). Comparative Efficacy, Speed and Adverse Effects of Three PTSD Treatments: Exposure Therapy, EMDR and Relaxation Training.

NICE (National Institute for Clinical Excellence). (2005). National Institute for Clinical Excellence: London, United Kingdom.

harianjoglosemar.com

pikiran-rakyat.com 